\title{
LOW-COST AND HIGH-SPEED ATMOSPHERIC PLASMA PROCESSING OF PEROVSKITE THIN FILMS
}

\author{
${ }^{1}$ Masoud SHEKARGOFTAR, ${ }^{2} J a n$ POSPIŚIL, ${ }^{3}$ Filip MUNZ, ${ }^{2}$ Petr DZIK, ${ }^{1}$ Tomáš HOMOLA \\ ${ }^{1} R \& D$ Center for Low-Cost Plasma and Nanotechnology Surface Modifications (CEPLANT), Department \\ of Physical Electronics, Faculty of Science, Masaryk University, Brno, Czech Republic, EU, \\ mshekargoftar@mail.muni.cz \\ ${ }^{2}$ Faculty of Chemistry, Brno University of Technology, Brno, Czech Republic, EU \\ ${ }^{3}$ Department of Condensed Matter Physics, Masaryk University, Brno, Czech Republic, EU
}

https://doi.org/10.37904/nanocon.2019.8588

\begin{abstract}
This study addresses the effects of atmospheric-pressure plasma on the properties of methylammonium lead halide perovskite thin films. Plasma-treated films then were used to fabricate an inverted p-i-n perovskite solar cell. The plasma treatment employed a large-area plasma of extremely high-volume power density, up to $100 \mathrm{~W} / \mathrm{cm}^{3}$, capable of generating diffuse, homogeneous and cool plasma $\left(<70{ }^{\circ} \mathrm{C}\right)$ in ambient air, as well as in other technical-grade gases including nitrogen, argon, methane, hydrogen, carbon dioxide and pure water vapour. Although the temperature of the plasma remained very low, the population of energetic states proved sufficient to induce both physical and chemical changes on the surfaces of perovskite films. The results demonstrate that plasma treatment leads to perovskite films with homogeneous surfaces. Photoluminescence measurement revealed that plasma treatment enhanced the intensity of peaks, a property that may be attributed to improved crystallinity. Most importantly, plasma treatment of perovskite films improved the performance of the perovskite solar cells.
\end{abstract}

Keywords: Low-temperature plasma, plasma treatment, DCSBD, methylammonium halide, perovskite solar cell

\section{INTRODUCTION}

Evaluation of the performance of perovskite solar cells (PSCs) has been the focus of considerable attention for the past 10 years. The power conversion efficiency (PCE) of PCSs has now achieved figures of over $25 \%$ [1]. Of all the perovskite materials, the halide perovskites, $\mathrm{CH}_{3} \mathrm{NH}_{3} \mathrm{X}_{3}(\mathrm{X}=\mathrm{I}, \mathrm{Cl}, \mathrm{Br})$, have emerged as key materials in the fabrication of high-efficiency solar cells [2]. Despite excellent improvements in efficiency, poor stability of PSCs under ambient conditions remains a significant challenge. Several strategies have been suggested for improving both the performance and stability of PSCs [3,4]. For example, some investigators have concentrated on replacing charge transport layers with new materials, while others have turned to alternative strategies such as solvent engineering, designing new kinds of solar cell structure, etc. Among all such studies, surface modification of the perovskite layers has proven a promising and effective method of tailoring the surface properties of perovskite films. Surface modification techniques can control surface morphology in such a way as to obtain homogeneous and highly crystallized perovskite layers. The enhancement of the surface morphology is revealed as a vital and viable approach to the fabrication of highly efficient PSCs of considerable durability [5,6].

Plasma modification of perovskite layers is emerging as a promising method for treatment of perovskite films. For instance, Chen et al. [7], reported that plasma treatment of methylammonium lead iodide led to an improvement in the PCE of a perovskite solar cell, from $10.32 \%$ to $14.29 \%$. Tsai el al. [8] showed that plasma treatment of perovskite film enhanced the power conversion efficiency of a PSC by $7.18 \%$, to $9.84 \%$. In this contribution, methylammonium lead halides $\left(\left.\mathrm{CH}_{3} \mathrm{NH}_{3}\right|_{3-x} \mathrm{Cl}_{x}\right)$ were subjected to nitrogen plasma treatment. The 
plasma was generated by diffuse coplanar surface barrier discharge (DCSBD), details of which discussed by Černák et al [9]. DCSBD has recently been investigated in the treatment of perovskite films and other nanolayers, such as $\mathrm{TiO}_{2}$ and $\mathrm{Al}_{2} \mathrm{O}_{3}$ [10-12]. This study focuses on the effects of plasma treatment on the morphological properties of perovskite films. These films were spin-coated onto quartz glass and measurements taken before and after plasma treatment. Inverted p-i-n structure PSCs were chosen to assess the effects of the plasma treatment on their performance.

\section{EXPERIMENTAL}

Methylammonium lead halide perovskite precursor was purchased from Ossila (UK). In order to study the effect of plasma treatment on the properties of perovskite, the precursor was spin-coated onto quartz glass $\left(1 \times 1 \mathrm{~cm}^{2}\right)$ and then annealed on a hotplate at a temperature of $80^{\circ} \mathrm{C}$ for 2 hours. Plasma treatment of the perovskite films was carried out by exposure to DCSBD plasma (RPS40, Roplass s.r.o., Czech Republic) in a nitrogen glove-box. A range of plasma treatment times were tested: $1 \mathrm{~s}, 2 \mathrm{~s}, 4 \mathrm{~s}$ and $8 \mathrm{~s}$; it was observed that plasma treatment for $2 \mathrm{~s}$ resulted in the most homogeneous surface and the best PCE. Plasma treatment for longer than $8 \mathrm{~s}$ led to deformation of the surface. Optimum treatment time was therefore considered to be $2 \mathrm{~s}$.

Steady-state photoluminescence $(\mathrm{PL})$ spectra in the visible wavelength were recorded using a RM1000 system (Renishaw, UK). Scanning electron microscopy (MIRA3 Tescan, Czech Republic) was employed to evaluate the surface morphology of the perovskite samples. The performance of the PSC devices was evaluated by using a system of AAA-certified Abet Sun solar simulator with an air mass (AM) 1.5G filter that simulated light intensity, adjusted to $1000 \mathrm{~W} / \mathrm{m}^{2}$ with an NREL-calibrated Si solar cell.

\section{RESULTS AND DISCUSSION}

The quality of perovskite films is one of the critical parameters affecting the efficiency of PSCs. Surface morphology and coverage may significantly influence the performance of the finished device [13]. Figure 1 presents the morphology of perovskite films before and after plasma treatment. Untreated perovskite film exhibited a non-homogeneous surface, with pinholes that might be attributed to the evaporation of solvent during thermal annealing. Plasma treatment led to larger perovskite grains and the surface became more homogenous compared with the untreated perovskite film. In addition, the number of pinholes significantly decreased after plasma treatment.

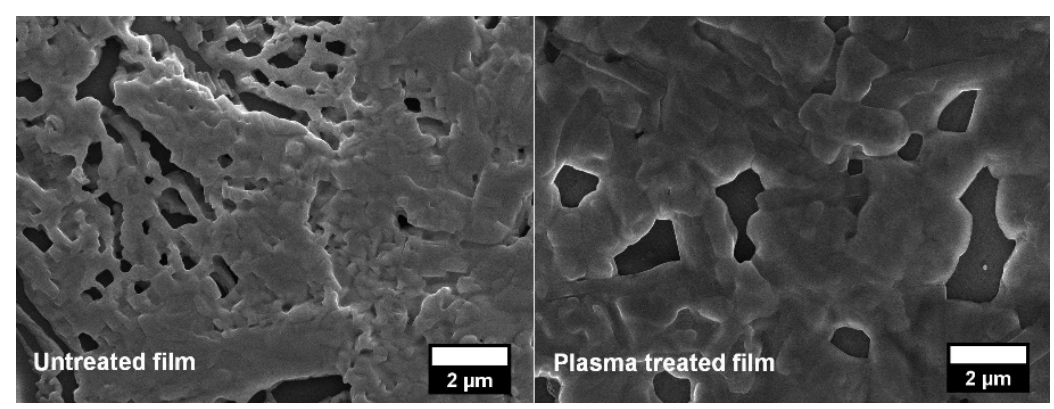

Figure 1 SEM images of perovskite films before and after plasma treatment

Figure 2 provides a comparative demonstration of the steady-state photoluminescence spectra of perovskite films. The untreated sample displays lower emission intensity, implying non-radiative recombination of excitons [14]. Plasma treatment led to a significant increase in PL intensity, which could imply an improved crystallinity of the perovskite film. In previous work, the authors observed that plasma treatment expanded crystal size and enhanced the crystallinity of perovskite films [10]. On the other hand, the full-width half-maximum (FWHM) of the peak remains constant, indicating that more generated excitons led to a stronger radiative recombination 
[15]. Since photoluminescence intensity indicates the ratio between radiative and non-radiative recombination, it may be concluded that increased radiative recombination and improved surface crystallinity with plasma treatment decreases non-radiative recombination.

Figure 3 demonstrates the J-V characteristics of the PSC device with plasma-treated film in comparison with the reference device with untreated perovskite film. The relevant parameters are listed in Table 1. The device with untreated perovskite film exhibited $V_{0 c} 721.57 \mathrm{~V}$ and Jsc $19.87 \mathrm{~mA} / \mathrm{cm}^{2}$, which resulted in an FF of $42.36 \%$ and PCE of $6.08 \%$. Plasma treatment of the perovskite film removed surface contamination, which led to better electrical conductivity and consequently $\mathrm{J}_{\mathrm{sc}}$ should therefore have improved. However, and surprisingly, the short current density fell $\left(\mathrm{Jsc}_{\mathrm{sc}} 18.23 \mathrm{~mA} / \mathrm{cm}^{2}\right)$ after plasma treatment. However, plasma treatment of the perovskite film increased $V_{O C}$ to $795.12 \mathrm{~V}$ and FF to $53.16 \%$. The increase in $\mathrm{V}_{\mathrm{OC}}$ and FF which could be attributed to reduction of carrier recombination after plasma treatment, was observed from PL measurement (above). This may suggest that plasma treatment of the perovskite film led to a reduction in charge recombination at the interface between the perovskite layer and the PCBM. The compensation between decreased $\mathrm{J}_{\mathrm{sc}}$ and increased $\mathrm{Voc}$ and FF resulted in an improved PCE of the PSC device from $6.08 \%$ to $7.76 \%$.

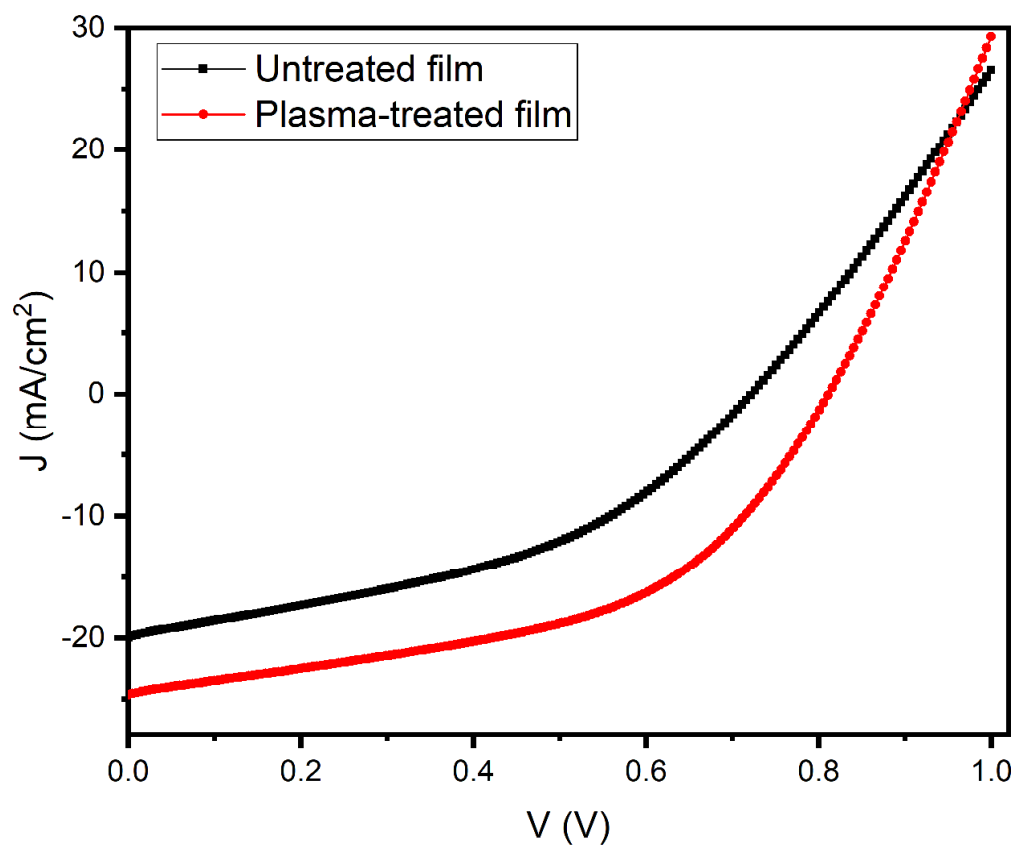

Figure $3 \mathrm{~J}-\mathrm{V}$ curves of fabricated perovskite devices 
Table 1 Performance parameters of PSCs

\begin{tabular}{lllll}
\hline & $\begin{array}{l}\mathrm{J}_{\mathbf{s c}} \\
\left(\mathrm{mA} / \mathrm{cm}^{2}\right)\end{array}$ & $\begin{array}{l}\mathbf{V}_{\text {oc }} \\
(\mathrm{mV})\end{array}$ & $\begin{array}{l}\text { FF } \\
(\%)\end{array}$ & $\begin{array}{l}\mathbf{\eta} \\
(\%)\end{array}$ \\
\hline Untreated & 19.87 & 721.57 & 42.36 & 6.08 \\
Plasma-treated & 18.23 & 795.12 & 53.16 & 7.76 \\
\hline
\end{tabular}

\section{CONCLUSION}

The effects of low-temperature plasma treatment on the surface properties of lead halide perovskite films were investigated. Perovskite films became more homogeneous with fewer pinholes in the surface after short plasma treatment. It was observed that plasma treatment increased the photoluminescence intensity of the perovskite films. Plasma treatment of the halide perovskite films is revealed as a promising post-treatment in the quest for high-efficiency perovskite solar cells. The results demonstrate that plasma treatment of the perovskite films led to improvement in the open-circuit voltage and fill factor of the PSCs, which could be attributed to improved charge transfer at the perovskite interface treated by plasma. The improved Voc and FF resulted in an improvement in the efficiency of the PSC from $6.08 \%$ to $7.76 \%$.

\section{ACKNOWLEDGEMENTS}

This research was supported by project L01411 (NPU I) funded by Ministry of Education, Youth and Sports of Czech Republic, project CZ.1.05/2.1.00/03.0086 funded by the European Regional Development Fund, and GACR project 19-14770Y.

\section{REFERENCES}

[1] L. Gao, I. Spanopoulos, W. Ke, S. Huang, I. Hadar, L. Chen, X. Li, G. Yang, M.G. Kanatzidis, Improved Environmental Stability and Solar Cell Efficiency of (MA,FA)Pbl 3 Perovskite Using a Wide-Band-Gap 1D Thiazolium Lead lodide Capping Layer Strategy, ACS Energy Lett. 4 (2019) 1763-1769. https://doi.org/10.1021/acsenergylett.9b00930.

[2] T.T. Ava, A. Al Mamun, S. Marsillac, applied sciences A Review : Thermal Stability of Methylammonium Lead Halide Based Perovskite Solar Cells, (2019). https://doi.org/10.3390/app9010188.

[3] B. Dou, J.B. Whitaker, K. Bruening, D.T. Moore, L.M. Wheeler, J. Ryter, N.J. Breslin, J.J. Berry, S.M. Garner, F.S. Barnes, S.E. Shaheen, C.J. Tassone, K. Zhu, M.F.A.M. Van Hest, Roll-to-Roll Printing of Perovskite Solar Cells, ACS Energy Lett. 3 (2018) 2558-2565. https://doi.org/10.1021/acsenergylett.8b01556.

[4] D.H. Kim, J.B. Whitaker, Z. Li, M.F.A.M. van Hest, K. Zhu, Outlook and Challenges of Perovskite Solar Cells toward Terawatt-Scale Photovoltaic Module Technology, Joule. 2 (2018) 1437-1451. https://doi.org/10.1016/j.joule.2018.05.011.

[5] N.J. Jeon, J.H. Noh, Y.C. Kim, W.S. Yang, S. Ryu, S. II Seok, Solvent engineering for high-performance inorganic-organic hybrid perovskite solar cells, Nat. Mater. 13 (2014) 897-903. https://doi.org/10.1038/nmat4014.

[6] Y. Li, L. Ji, R. Liu, C. Zhang, C.H. Mak, X. Zou, H.H. Shen, S.Y. Leu, H.Y. Hsu, A review on morphology engineering for highly efficient and stable hybrid perovskite solar cells, J. Mater. Chem. A. 6 (2018) 12842-12875. https://doi.org/10.1039/c8ta04120b.

[7] Z.C. Chen, Y. Cheng, C.C. Lin, C.S. Li, C.C. Hsu, J.Z. Chen, C.I. Wu, I.C. Cheng, In-situ atmospheric-pressure dielectric barrier discharge plasma treated $\mathrm{CH} 3 \mathrm{NH} 3 \mathrm{Pbl} 3$ for perovskite solar cells in regular architecture, Appl. Surf. Sci. 473 (2019) 468-475. https://doi.org/10.1016/j.apsusc.2018.12.118.

[8] J.H. Tsai, I.C. Cheng, C.C. Hsu, C.C. Chueh, J.Z. Chen, Feasibility study of atmospheric-pressure dielectric barrier discharge treatment on $\mathrm{CH}_{3} \mathrm{NH}_{3} \mathrm{Pbl}_{3}$ films for inverted planar perovskite solar cells, Electrochim. Acta. 293 (2019) 1-7. https://doi.org/10.1016/j.electacta.2018.09.203. 
[9] M. Černák, D. Kováčik, J. Ráhel', P. St’ahel, A. Zahoranová, J. Kubincová, A. Tóth, L. Černáková, Generation of a high-density highly non-equilibrium air plasma for high-speed large-area flat surface processing, Plasma Phys. Control. Fusion. 53 (2011) 124031. https://doi.org/10.1088/0741-3335/53/12/124031.

[10] M. Shekargoftar, J. Jurmanová, T. Homola, A Study on the Effect of Ambient Air Plasma Treatment on the Properties of Methylammonium Lead Halide Perovskite Films, 9 (2019). https://doi.org/10.3390/met9090991.

[11] M. Shekargoftar, P. Dzik, Z. Ďurašová, M. Stupavská, D. Pavliňák, T. Homola, Mineralization of flexible mesoporous $\mathrm{TiO}_{2}$ photoanodes using two low-temperature DBDs in ambient air, (2018) 1-9. https://doi.org/10.1002/ctpp.201700213.

[12] E. Mudra, M. Streckova, D. Pavlinak, V. Medvecka, D. Kovacik, A. Kovalcikova, P. Zubko, V. Girman, Z. Dankova, V. Koval, J. Duzsa, Development of $\mathrm{Al}_{2} \mathrm{O}_{3}$ electrospun fibers prepared by conventional sintering method or plasma assisted surface calcination, Appl. Surf. Sci. 415 (2017) 90-98. http://dx.doi.org/10.1016/j.apsusc.2016.11.162.

[13] D. Yang, R. Yang, K. Wang, C. Wu, X. Zhu, J. Feng, X. Ren, G. Fang, S. Priya, S. (Frank) Liu, High efficiency planar-type perovskite solar cells with negligible hysteresis using EDTA-complexed $\mathrm{SnO}_{2}$, Nat. Commun. 9 (2018). https://doi.org/10.1038/s41467-018-05760-x.

[14] S. Shao, J. Liu, G. Portale, H.H. Fang, G.R. Blake, G.H. ten Brink, L.J.A. Koster, M.A. Loi, Highly Reproducible Sn-Based Hybrid Perovskite Solar Cells with 9\% Efficiency, Adv. Energy Mater. 8 (2018). https://doi.org/10.1002/aenm.201702019.

[15] N.D. Pham, V.T. Tiong, P. Chen, L. Wang, G.J. Wilson, J. Bell, H. Wang, Enhanced perovskite electronic properties via a modified lead(ii) chloride Lewis acid-base adduct and their effect in high-efficiency perovskite solar cells, J. Mater. Chem. A. 5 (2017) 5195-5203. https://doi.org/10.1039/c6ta11139d. 